\title{
Effects of Environmental Wind on Natural Smoke Exhaust in a Tunnel with One Blocked End
}

\author{
Lu CHEN ${ }^{\mathrm{a}}$, Miaocheng WENG ${ }^{\mathrm{a}, \mathrm{b}, \mathrm{c}, 1}$, Fang LIU ${ }^{\mathrm{a}, \mathrm{b}, \mathrm{c}}$ \\ a School of Civil Engineering, Chongqing University, Chongqing 400045, China \\ ${ }^{\mathrm{b}}$ Key Laboratory of New Technology for Construction of Cities in Mountain Area of \\ Ministry of Education (Chongqing University), Chongqing 400045, China \\ c Joint International Research Laboratory of Green Buildings \& Built Environments, \\ Chongqing 400045, China
}

\begin{abstract}
In order to investigate the effect of environmental wind on a tunnel with one blocked end fire under natural ventilation, a series of numerical simulations were conducted using large eddy simulation method in this study. The tunnel model is established by using the numerical simulation software FDS, and 36 groups of working conditions such as wind speed of $0-5 \mathrm{~m} / \mathrm{s}$ and wind angle of $45-135$ are simulated. Combined with the simulation results of smoke spread, temperature and velocity vector, the smoke flow characteristics and temperature distribution characteristics in the tunnel with one blocked are analyzed, and some effects of the changes of ambient wind speed and direction on natural smoke exhaust in a tunnel with one blocked end are obtained.
\end{abstract}

Keywords. Tunnel with one blocked end, environmental wind, natural ventilation, smoke flow

\section{Introduction}

With the deepening of urbanization, a large number of urban population increases. Various tunnels not only bring convenient transportation to people, but also bring new challenges to fire prevention and control work. In recent years, one end sealing tunnel has been gradually applied in engineering. Due to its special structural form, there is no specific regulation on its ventilation and smoke exhaust system in relevant codes. In addition, there are relatively few researches on its ventilation and smoke exhaust system. Therefore, it has important theoretical significance and engineering application value to carry out the smoke control research of tunnel with one end blocked.

Some scholars have studied the smoke flow characteristics and temperature distribution of fire in blocked tunnels. Hu et al. [1] studied the distribution of $\mathrm{CO}$ concentration field after a fire in such buildings through a full-size experiment in a long passageway under a certain place, and the results showed that $\mathrm{CO}$ concentration increased linearly with the increase of the height from the ground, and decreased exponentially with the increase of the distance from the fire source. Han et al. [2] studied

1 Corresponding Author, Miaocheng WENG, School of Civil Engineering, Chongqing University, Chongqing 400045, China; E-mail: 416540297@qq.com. 
the influence of slope on temperature attenuation of downstream roof of tunnel fire source blocked at one end through small-size experiments and numerical simulation, and the research results showed that the influence of tunnel slope change on temperature attenuation increased with the increase of distance from fire source. Weng et al. [3] carried out full-size experiments in an open one-way tunnel at one end and studied smoke flow characteristics of subway fire emergency vents under different operation modes, providing reference for engineering design of related buildings.

In addition, some experts and scholars also studied the influence of tunnel sealing ratio and asymmetric sealing on fire source behavior and temperature characteristics of smoke in tunnel. Yao et al. [4] conducted small-size model experiments to study the influence of fire source location in a closed tunnel on the maximum temperature of smoke inside the tunnel.

As can be seen from the above study on non-open tunnels at both ends, researchers mainly studied the influence of internal characteristics and ventilation forms of tunnels on fire smoke, and did not involve the possible influence of external wind of tunnels. In fact, some studies on conventional tunnels by scholars found that the influence of ambient wind outside the tunnel on tunnel fire can not be ignored.

Fan[5, 6] conducted a series of numerical simulations to study the influence of ambient wind on tunnel fire under natural ventilation of shaft. Fan's research shows that the spread speed of smoke is mainly affected by HRR rather than ambient wind speed. Zhao[7] studied the influence of ambient cross wind and longitudinal ventilation wind velocity on smoke characteristics in tunnel through small-scale experiment. The results show that the smoke countercurrent length decreases with the increase of longitudinal wind speed, and the critical wind speed and smoke countercurrent length increase with the increase of ambient cross wind speed.

For tunnel fire, when there is ambient wind at the tunnel port directly connected to the outside world, the wind pressure will affect the pressure difference inside and outside the tunnel, so that the gas flow characteristics inside the tunnel are different from those in no wind environment.

On the basis of FDS simulation of the flow field in the tunnel affected by external wind, Yi[8] et al. carried out small-size experiments and obtained a dimensionless flame length prediction model under the influence of environmental wind. Chen[9] 's research shows that the gas flow characteristics in tunnels induced by ambient wind are mainly affected by the hydraulic diameter of the tunnel, and there is little difference in gas flow characteristics in tunnels with different shapes but the same hydraulic diameter. Yao[10] studied the influence of ambient wind on the pool fire combustion characteristics (MLRPUA) in the open environment and tunnel. Liang[11] used a new particle image flow field visualization (PIFFV) technology to study the influence of ambient wind on the motion characteristics of indoor fire smoke and the performance of natural smoke extraction. Tanaka[12] established a 1:12 scale model tunnel to evaluate the influence of transverse environmental wind at the top opening on fire smoke diffusion in shallow buried urban road tunnels.

In addition to the speed of ambient wind, the change of ambient wind direction will also affect the flow field in the tunnel, which will affect the combustion behavior and the spread of fire smoke. The environmental wind direction here is defined as the Angle between the direction from which the environmental wind blows and the tunnel axis (as shown in figure 1). As early as 2011, Nyman and Sandberg[13] used wind tunnel experiments to study the variation of flow fields in tunnels under different environmental winds. The main influence of environmental wind direction on the flow field in the tunnel 
is the fluctuation of tunnel inlet pressure. Therefore, Kubwimana et al. [14] studied the influence of environmental wind direction on the pressure distribution at the tunnel inlet through wind tunnel experiment and CFD simulation. Ao Jiao[15] used scale experiments to reveal the influence of the deflection Angle between the ambient wind and the tunnel on the combustion characteristics of tunnel fire sources. It was found that when the deflection Angle was between $45^{\circ}$ and $90^{\circ}$, the mass combustion rate decreased with the increase of the deflection Angle. When the deviation Angle is greater than $90^{\circ}$, the mass combustion rate remains relatively stable. Shen[16] used ethanol tank fire combustion experiment to study the influence of the deviation Angle between the ambient wind and the tunnel on the length of smoke countercurrent, the maximum ceiling temperature in the tunnel and the maximum ceiling temperature location.

It can be concluded that the ambient wind outside the tunnel has a significant influence on the combustion behavior and smoke diffusion in the tunnel. Therefore, in order to improve and supplement the existing research on tunnel ventilation and smoke exhaust, it is necessary to study the smoke flow characteristics in the tunnel under the influence of ambient wind in detail. Therefore, in this study, a series of simulations were carried out through FDS to study the influence of ambient wind on smoke flow characteristics of natural ventilation in a tunnel with one end blocked.

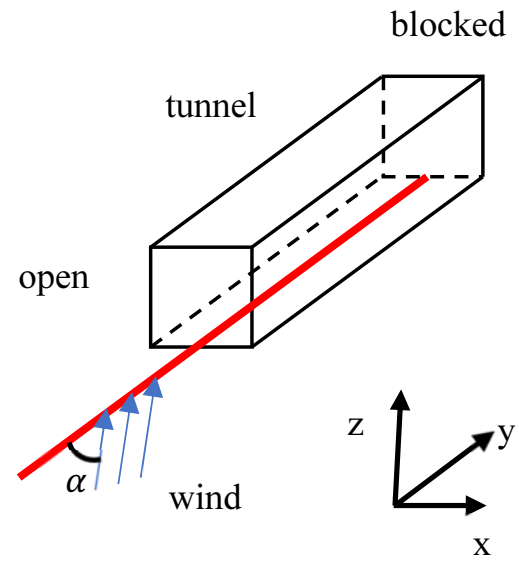

a) stereogram

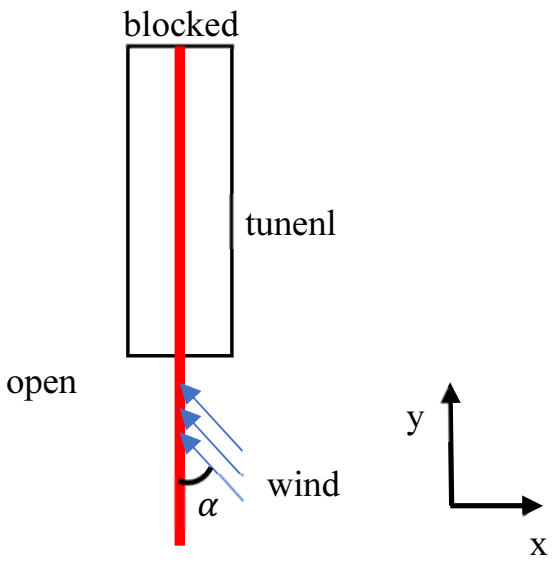

b) vertical view

Figure 1. Direction of ambient wind

\section{Numerical Modeling}

\subsection{Fire Dynamics Simulator}

FDS is a professional software developed by the National Institute of Standards and Technology (NIST) for fire simulation research. It can implement direct numerical 
simulation (DNS) and large Eddy simulation (LES) based on Navier -- Stokes equations. The LES model, which is widely used in the study of fire smoke flow characteristics, is used for numerical simulation of fire in this paper.

The simulation mechanism of FDS software satisfies the following basic conservation equation, as shown below:

(1) The conservation of mass:

$$
\frac{\partial \rho}{\partial t}+\nabla \cdot \rho \vec{u}=m_{b}^{\prime \prime \prime}
$$

(2) The conservation of momentum:

$$
\frac{\partial u}{\partial t}-\vec{u} \times \omega+\nabla H-\tilde{p} \nabla(1 / \rho)=\frac{1}{\rho}\left[\left(\rho-\rho_{\infty}\right) g+f_{b}+\nabla \cdot \tau\right]
$$

(3) The conservation of energy:

$$
\frac{\partial}{\partial t}\left(\rho h_{s}\right)+\nabla \cdot \rho h_{s} \vec{u}=\frac{D \tilde{p}}{D t}+\dot{q}^{\prime \prime \prime}-\nabla \cdot \dot{q}^{\prime \prime}
$$

(4) Ideal gas equation of state:

$$
p=\frac{\rho R T}{M}
$$

\subsection{Model}

The schematic diagram of the model is shown in figure 2. The length, width, and height of the tunnel are $110 \mathrm{~m}, 10 \mathrm{~m}$, and $5 \mathrm{~m}$ respectively. In simulation, the material of tunnel walls, shafts and other enclosures is set as "Concret". Take the Open end of the tunnel as the coordinate origin $X=0 \mathrm{~m}$ and set its attribute to "Open". The fire source center is located in the tunnel center $\left(X_{f}=55 \mathrm{~m}\right)$. The heat release rate of the fire source is $2 \mathrm{MW}$. Thermocouples are arranged at $0.1 \mathrm{~m}$ intervals below the ceiling of the central tunnel, and 110 temperature measuring points are arranged in total. Temperature, speed and visibility slices are set at $\mathrm{Y}=5 \mathrm{~m}$. The ambient temperature was set as $20{ }^{\circ} \mathrm{C}$ and the ambient pressure was set as $101 \mathrm{kPa}$. The open end of the tunnel is equipped with an extension domain, and the ambient wind is simulated by setting its boundary. Jing et al. [17] conducted long-term field measurement of wind environment on a bridge located in the valley, and found that the wind speed of ambient wind outside the tunnel remained unchanged at a certain height, so it was reliable to use a stable wind speed to simulate the ambient wind outside the tunnel under actual conditions. In total, 36 cases were simulated, as summarized in table 1.

LES model is used in FDS, and the accuracy of numerical simulation results is determined by the reasonable setting of grid size. In general, the decrease of grid size brings the improvement of calculation accuracy, but also the increase of calculation time. Therefore, when conducting FDS numerical simulation, it is necessary to select appropriate grid size and shorten the calculation time as much as possible on the premise of ensuring simulation accuracy. In the experimental FDS software for fire simulation, the conventional method for judging grid quality is to calculate $D^{*} / \delta x$, and the expression of $D^{*}$ is: 


$$
D^{*}=\left(\frac{Q}{\rho_{a} c_{p} T_{a} \sqrt{g}}\right)^{\frac{2}{5}}
$$

Where $Q$ is the heat release rate of the fire, and $\rho_{a}$ is the air density, $c_{p}$ is the constantpressure specific heat of air, $T_{a}$ is ambient temperature and $g$ it the acceleration of gravity.

A large number of studies have shown that when the value of $D^{*} / \delta x$ is in the range of $4 \sim 16$, the simulation accuracy can be satisfied while the calculation time is not too long. In this paper, $0.2 \mathrm{~m}$ is taken as the grid size, which can meet the requirement that the value of $D^{*} / \delta x$ is in the range of $4 \sim 16$.

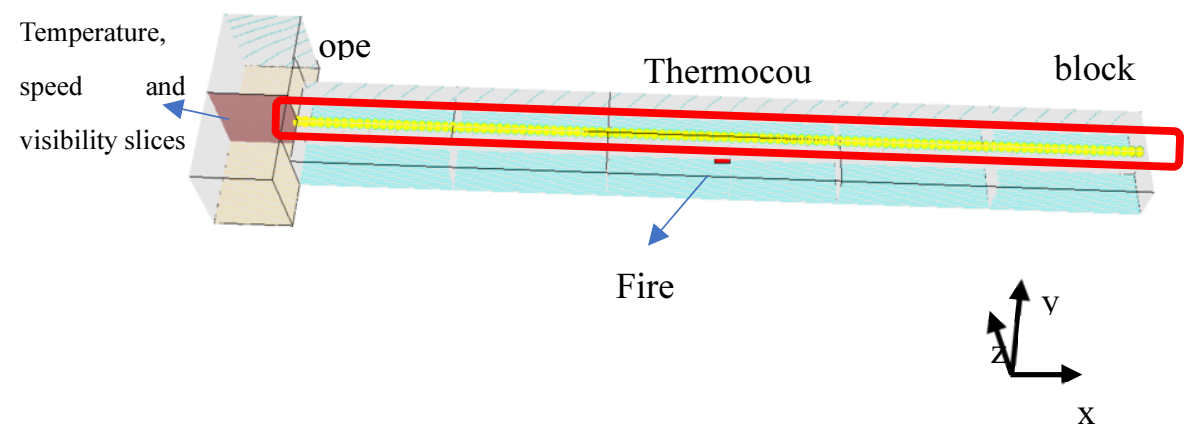

Figure 2. FDS model configuration

Table 1. Simulation conditions

\begin{tabular}{cccc}
\hline No. & HHR $($ MW $)$ & $\boldsymbol{v}(\mathbf{m} / \mathbf{s})$ & $\boldsymbol{\alpha}\left(^{\circ}\right)$ \\
\hline Case 0 & & 0 & $\backslash$ \\
Case $1 \sim$ Case 5 & & $1 \sim 5$ & 45 \\
Case6 $\sim$ Case10 & & $1 \sim 5$ & 60 \\
Case11 $\sim$ Case15 & 2 & $1 \sim 5$ & 75 \\
Case16 $\sim$ Case20 & & $1 \sim 5$ & 90 \\
Case21 $\sim$ Case25 & & $1 \sim 5$ & 105 \\
Case26 $\sim$ Case30 & & $1 \sim 5$ & 120 \\
Case31 $\sim$ Case35 & $1 \sim 5$ & 135 \\
\hline
\end{tabular}

\section{Results and Discussion}

\subsection{Effect of Ambient Wind Speed on Smoke Flow Characteristics}

Figure 3 is the side view of smoke flow under different environmental wind speed and wind direction simulation schemes. Where, $v$ is environmental wind speed and $\alpha$ is the included angle between environmental wind and tunnel axial direction. Figure 3 shows that when there is no ambient wind at the open end of the tunnel, that is, when the ambient wind speed $v=0 \mathrm{~m} / \mathrm{s}$, the smoke layer upstream of the fire source is relatively stable. The downstream of the fire source has an adverse effect on the discharge of smoke due to its proximity to the sealing end, and the smoke sinks to a certain extent, but it can 
basically maintain a relatively stable stratified state. It can also be seen from figure 3 that, with the generation of ambient wind outside the tunnel, the smoke layer in the tunnel, especially the upstream of the fire source, is difficult to maintain stability, and with the increase of wind speed, the stability of the smoke layer in the tunnel under all wind directions $\left(45^{\circ} \leq \alpha \leq 135^{\circ}\right)$ decreases.

When the ambient wind speed at the exit of the tunnel increases to $1 \mathrm{~m} / \mathrm{s}$, the smoke layer at the upstream of the fire source is still in a relatively stable state, and there are some reflux smoke at the end of the tunnel, and the smoke layer tends to be chaotic. When the ambient wind speed at the tunnel exit increases to $2 \mathrm{~m} / \mathrm{s}$, there are more backflow smoke at the end of the tunnel, the stratification of smoke is not obvious, and the smoke fills the whole tunnel. Since then, with the further increase of the environmental wind speed at the tunnel exit, the chaos degree of the smoke layer is further increased.

Environmental wind can both promote and hinder the flow of smoke in the tunnel (see 3.2 correlation analysis). However, it can be seen from figure 3 that regardless of the size of wind direction Angle $\alpha\left(45^{\circ} \leq \alpha \leq 135^{\circ}\right)$, the natural discharge of smoke becomes more difficult with the increase of environmental wind speed. Therefore, it is not difficult to infer: With the increase of ambient wind speed, the growth of its obstruction effect on smoke emission is greater than that of its promotion effect on smoke emission.

By observing the velocity vector diagram at $\mathrm{Y}=5 \mathrm{~m}$ section (figure 4 ), it can be found that with the increase of wind speed, the disturbance of ambient wind to the flow field in the tunnel gradually increases. The turbulence of the smoke flow near the open end of the tunnel increases with the increase of wind speed.

When $v>0 \mathrm{~m} / \mathrm{s}$, vortex flow appears at the open end of tunnel. With the increase of ambient wind speed, the vortex area gradually expands into the tunnel. When $v=5$ $\mathrm{m} / \mathrm{s}$, the flow field near the tunnel opening has been completely disorganized. The disturbance degree of ambient wind to the original stable smoke flow increases with the wind speed, which is the main reason why natural smoke exhaust becomes more difficult with the increase of ambient wind speed.

\subsection{Effect of Ambient Wind Direction on Smoke Flow Characteristics}

According to the relevant theory of fluid mechanics, the ambient wind at the tunnel mouth may have two influences on the airflow in the tunnel: on the one hand, the ambient wind will form negative pressure (or negative pressure) at the tunnel mouth, which will promote (hinder) the discharge of smoke; On the other hand, the environmental wind is inconsistent with the original direction of the smoke flow, which will disturb the natural exhaust of the smoke flow and hinder the exhaust of the smoke.

When $45^{\circ}<\alpha \leq 90^{\circ}$, the ambient wind has a velocity component towards the tunnel, and this velocity component decreases with the increase of $a$. Meanwhile, the resistance of the ambient wind to the exhaust of the smoke flow in the tunnel also decreases (figure 3 (a) $\sim 3(\mathrm{~d})$ ).

When $90^{\circ}<\alpha \leq 135^{\circ}$, the velocity component of the ambient wind in the $\mathrm{X}$ direction is toward the outside of the open end of the tunnel. The increase of a increases the negative pressure at the tunnel mouth, thus strengthening the promoting effect of environmental wind on smoke discharge (figure 3 (e) figure 3 (f)).

Therefore, at a constant ambient wind speed, the natural smoke extraction capacity 
in the tunnel increases with the increase of $\alpha\left(45^{\circ} \leq \alpha \leq 135^{\circ}\right)$.

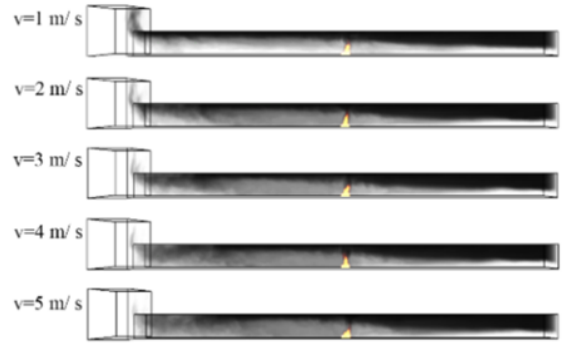

(a) $\alpha=45^{\circ}$

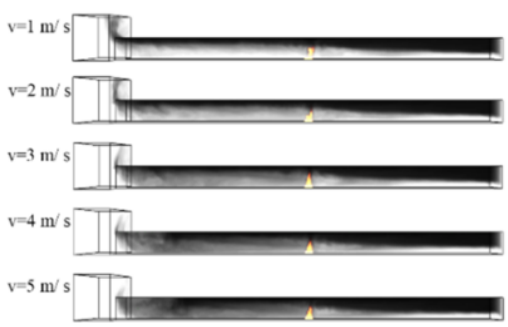

(c) $\alpha=75^{\circ}$

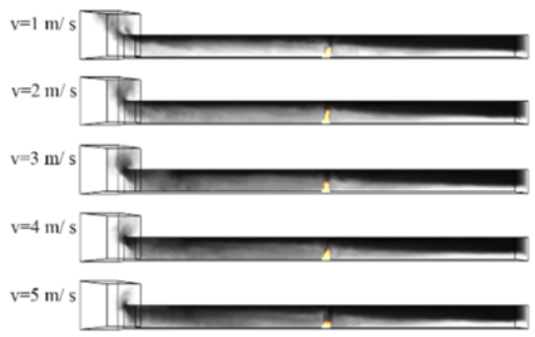

(e) $\alpha=105^{\circ}$

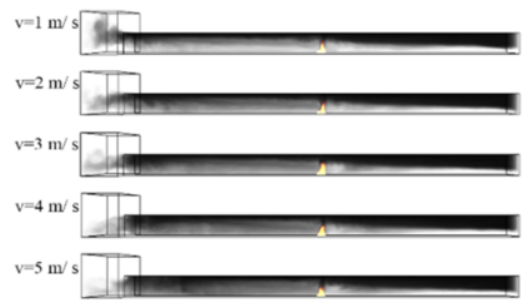

(g) $\alpha=135^{\circ}$

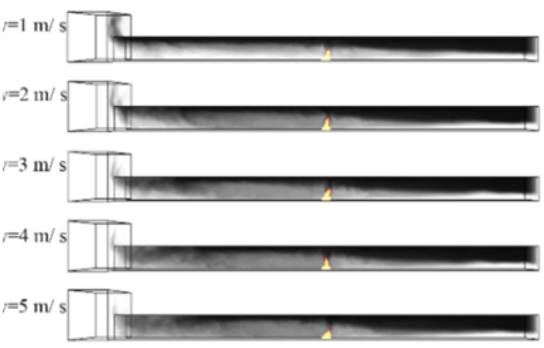

(b) $\alpha=60^{\circ}$

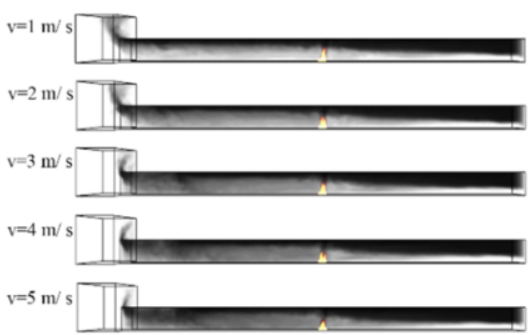

(d) $\alpha=90^{\circ}$

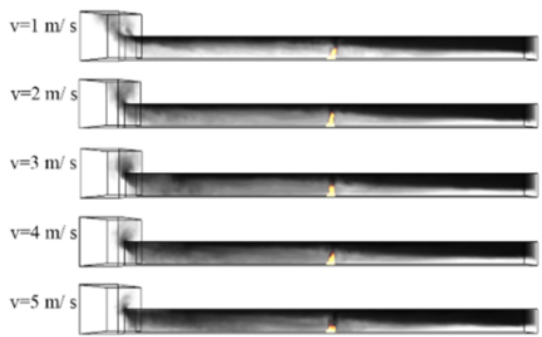

(f) $\alpha=120^{\circ}$

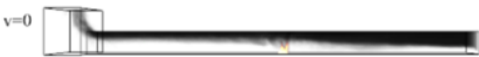

Figure 3. Side view of smoke flow 


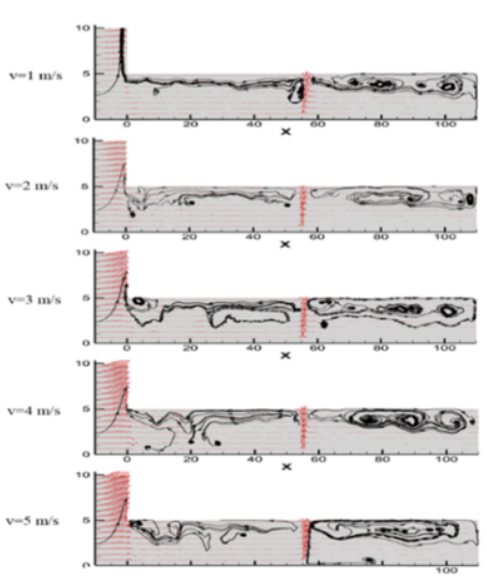

(a) $\alpha=45^{\circ}$

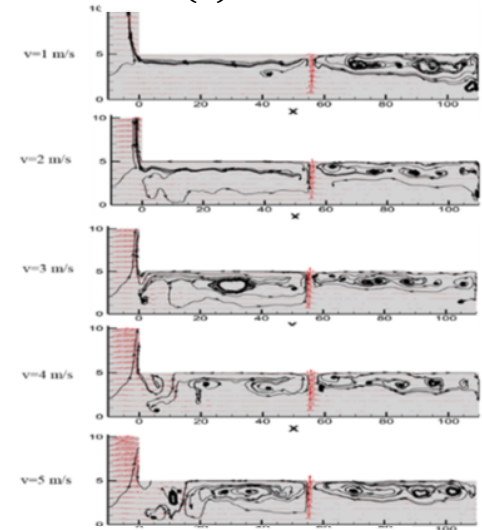

(c) $\alpha=75^{\circ}$

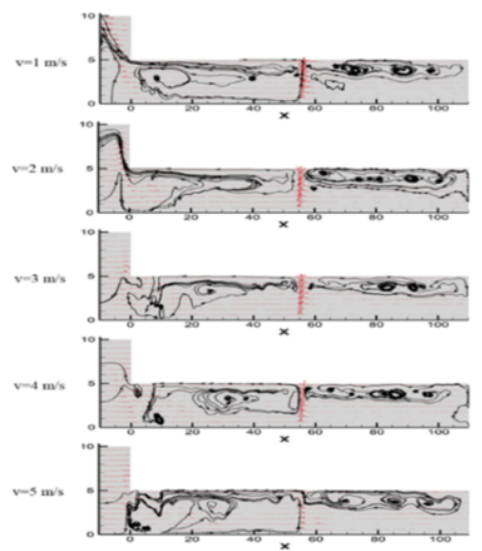

(e) $\alpha=105^{\circ}$

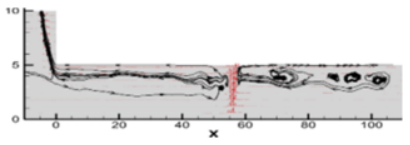

(g) $\alpha=135^{\circ}$

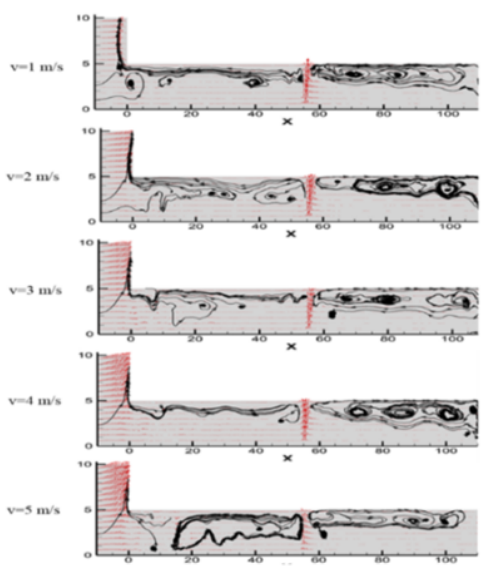

(b) $\alpha=60^{\circ}$
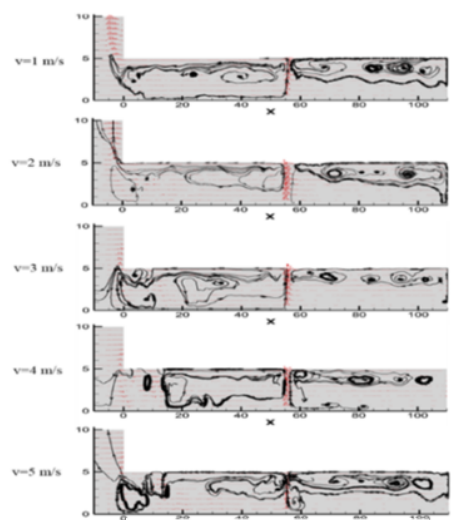

(d) $\alpha=90^{\circ}$
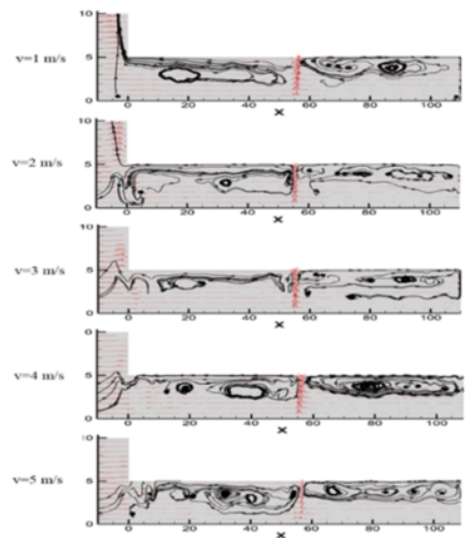

(f) $\alpha=120^{\circ}$ 


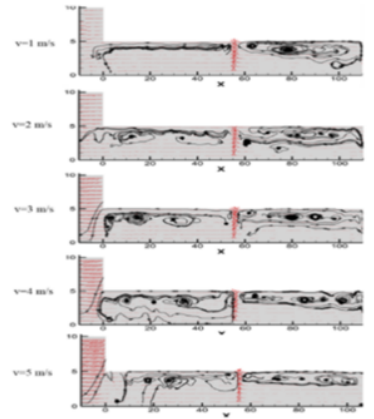

(h) $\alpha=135^{\circ}$

Figure 4. Velocity vector field in $\mathrm{Y}=5 \mathrm{~m}$ slice

\subsection{Effect of Ambient Wind on the Temperature in Tunnel}

Figure 5 shows the temperature distribution of $\mathrm{Y}=5 \mathrm{~m}$ slice under different environmental wind speeds and directions. The temperature change in the tunnel after the fire is mainly affected by the diffusion of hot smoke, so the distribution of temperature is closely related to the flow of smoke in the tunnel.

It can be seen from figure 5(h) that when the ambient wind speed $v=0 \mathrm{~m} / \mathrm{s}$, the temperature has a stable stratification along the tunnel ceiling. Due to the good natural ventilation and smoke exhaust conditions near the open end of the tunnel, the hot smoke is easy to discharge and the hot smoke layer is thin. The sealing side obstructs the natural discharge of hot smoke, and the layer of hot smoke is thicker. Overall, the hot smoke layer has a trend of gradually thickening from the open end to the sealing end along the tunnel.

At low wind speed $(v=1 \mathrm{~m} / \mathrm{s})$, the ambient wind outside the tunnel has limited influence on the temperature distribution inside the tunnel, and the temperature distribution is slightly disturbed, but the overall change is not much compared with that without wind.

As the wind speed continues to increase, the temperature distribution is disturbed more. It can be seen from figure 5 that when $v \geq 3 \mathrm{~m} / \mathrm{s}$, the temperature of the ceiling near the tunnel opening decreases, while the temperature at the lower level rises slightly.

When $v=0 \mathrm{~m} / \mathrm{s}$, the smoke is only under the action of hot pressure and can form a stable layer of smoke to discharge the tunnel from the tunnel outlet. However, if $v>$ $0 \mathrm{~m} / \mathrm{s}$, the flow of smoke is hindered by the ambient wind, and part of the ambient air flows into the tunnel and exchange heat with the smoke, leading to the temperature reduction, which also explains the reason why the ceiling temperature drops near the tunnel mouth when the wind speed reaches a certain level $(v \geq 3 \mathrm{~m} / \mathrm{s})$.

Table 2 is the data of ceiling maximum temperature under different ambient wind conditions of tunnel blocked at one end. On average, the maximum ceiling temperature is less sensitive to the change of ambient wind speed than to the change of ambient wind direction. A simple variance analysis of the data (table 3) shows that: With $95 \%$ 
confidence, wind direction can be considered to have an effect on the maximum ceiling temperature of the tunnel blocked at one end.

Table 2. ceiling maximum temperature $\left({ }^{\circ} \mathrm{C}\right)$

\begin{tabular}{cc|cccccc}
\hline & & \multicolumn{7}{|c}{$\boldsymbol{v}(\mathbf{m} / \mathbf{s})$} \\
& & $\mathbf{1}$ & $\mathbf{2}$ & $\mathbf{3}$ & $\mathbf{4}$ & $\mathbf{5}$ & Average \\
\hline \multirow{3}{*}{$\alpha\left(^{\circ}\right)$} & 45 & 311.7 & 315.2 & 314.4 & 309.6 & 305.4 & 311.26 \\
& 60 & 312.9 & 318.4 & 311.7 & 315.9 & 310.1 & 313.80 \\
& 75 & 323.8 & 330.3 & 323.3 & 318.6 & 314.3 & 322.06 \\
& 90 & 323.7 & 319.6 & 328.5 & 322.3 & 322.6 & 323.34 \\
& 105 & 316.7 & 328.3 & 316.7 & 316.1 & 323.7 & 320.30 \\
& 120 & 319.7 & 310.1 & 328.4 & 321.4 & 316.9 & 319.30 \\
& 135 & 322.6 & 334.6 & 320.0 & 341.3 & 348.5 & 333.40 \\
& Average & 318.73 & 322.36 & 320.43 & 320.74 & 320.21 & \\
\hline
\end{tabular}

Table 3. variance analysis

\begin{tabular}{ccccccc}
\hline Source & SS & df & MS & F & P-value & F crit \\
\hline$\alpha$ & 1640.833 & 6 & 273.4722 & 5.398121 & 0.001188 & 2.508189 \\
$v$ & 56.41475 & 4 & 14.10369 & 0.278395 & 0.889035 & 2.776289 \\
Error & 1215.855 & 24 & 50.66063 & & & \\
Total & 2913.103 & 34 & & & & \\
\hline
\end{tabular}

According to figure 6 , the maximum ceiling temperature changes with the wind $\alpha$ As the ambient wind speed increases, the maximum ceiling temperature shows an upward trend as a whole, and the upward trend is more obvious with the increase of ambient wind speed, but the upward trend will produce a mutation at $\alpha=90^{\circ}$ (mark position in figure 6). The mutation may be caused by the longitudinal wind speed induced by ambient wind when $\alpha$ is around $90^{\circ}$. This result is similar to that found by Shen[16] in the study of conventional tunnels with open ends.

Based on previous studies, we know that the dimensionless ceiling maximum temperature rise $T^{*}$ satisfies the following formula

$$
T^{*}=\frac{T_{\max }-T_{a}}{T_{a}}=f\left(Q, \rho_{a}, c_{p}, g, H, u, D_{f}, L, d, v, \alpha\right)
$$

In this study, $Q, \rho, c_{p}, g, H, D_{f}, L$ and $d$ are fixed values, and the longitudinal wind $u$ in the tunnel is directly induced by the ambient wind $v$ so $T^{*}$ meets the following formula

$$
T^{*}=f(v, \alpha)
$$

It is possible that when the outlet of one end of the tunnel is blocked, the air flow induced by ambient wind will decay rapidly with the distance from the open section of the tunnel. Therefore, in the case of this study, the ambient wind speed has no significant effect on the maximum temperature of the tunnel ceiling.

Under the experimental conditions in this paper, it can be assumed that $T^{*}$ is single valued function of $\alpha$. 

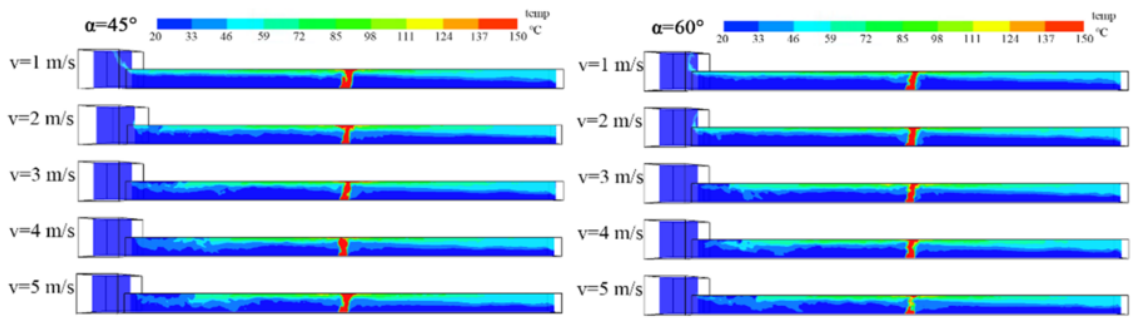

(a) $\alpha=45^{\circ}$

(b) $\alpha=60^{\circ}$
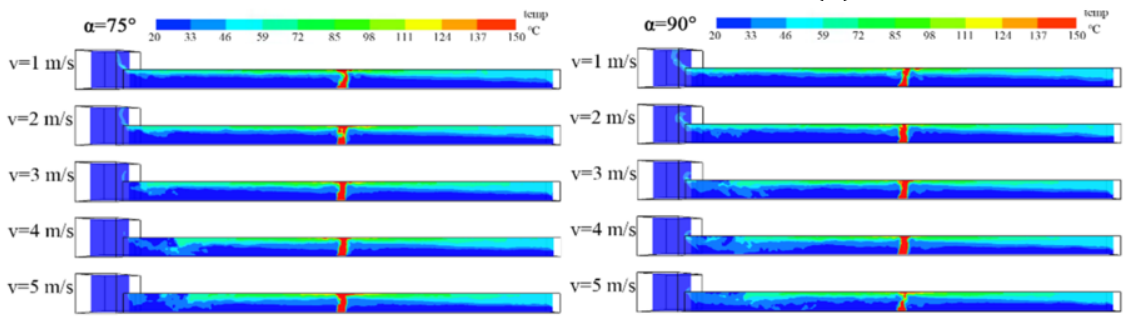

(c) $\alpha=75^{\circ}$

(d) $\alpha=90^{\circ}$

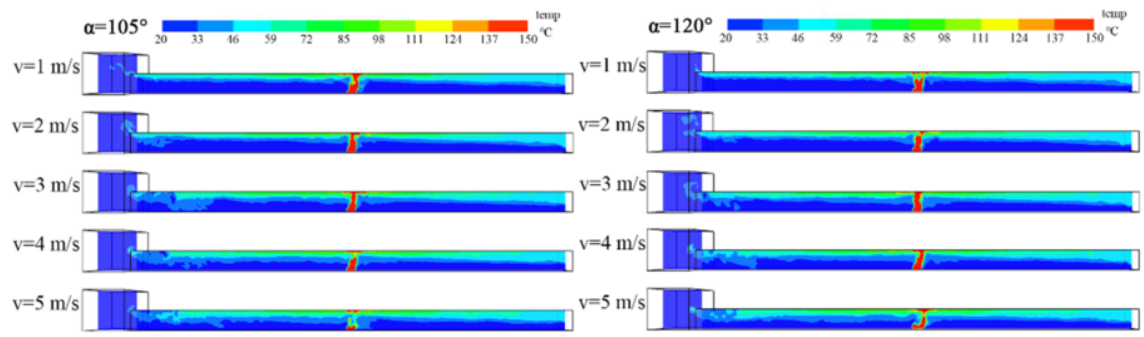

(e) $\alpha=105^{\circ}$

(f) $\alpha=120^{\circ}$

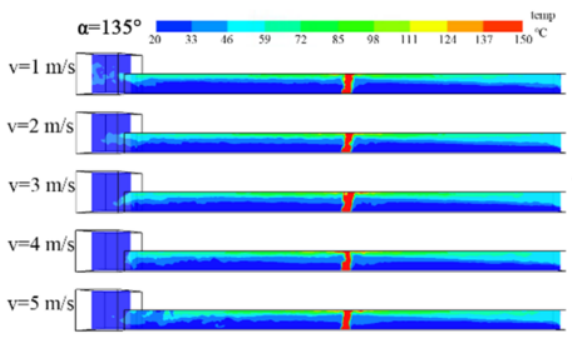

(g) $\alpha=135^{\circ}$

(h) $v=0 \mathrm{~m} / \mathrm{s}$

Figure 5. Temperature distribution in $\mathrm{Y}=5 \mathrm{~m}$ slice.

As shown in figure 7 that $T^{*}$ increases linearly with the increasing $\alpha$ under the constant wind speed ( $v=2 \mathrm{~m} / \mathrm{s}, R^{2}=0.2441$, which may be the error caused by the abnormal fluctuation of ceiling temperature). Therefore, it can be considered that under the experimental conditions of this paper, $T^{*}$ in one end blocked tunnel follows $\alpha$ It 
changes linearly $\left(45^{\circ} \leq \alpha \leq 90^{\circ}\right)$

Figure 8 is the regression analysis of the maximum temperature rise of dimensionless ceiling under different wind speeds and wind directions with respect to wind direction angle $\alpha$. As shown in figure 8, the linear regression coefficient $R^{2}$ is only 0.5948 , which is quite different from that under constant wind $\operatorname{speed}\left(R^{2} \geq 0.7945\right)$. Based on the above facts, it can be found that the ambient wind speed actually has an impact on the ceiling maximum temperature, which can be seen from Shen's conclusion[16]. The previous analysis shows that the impact of wind speed on the maximum ceiling temperature is not significant, which may be because the fire source is too far away from the tunnel outlet, and the blocking effect reduces the impact of wind speed change.
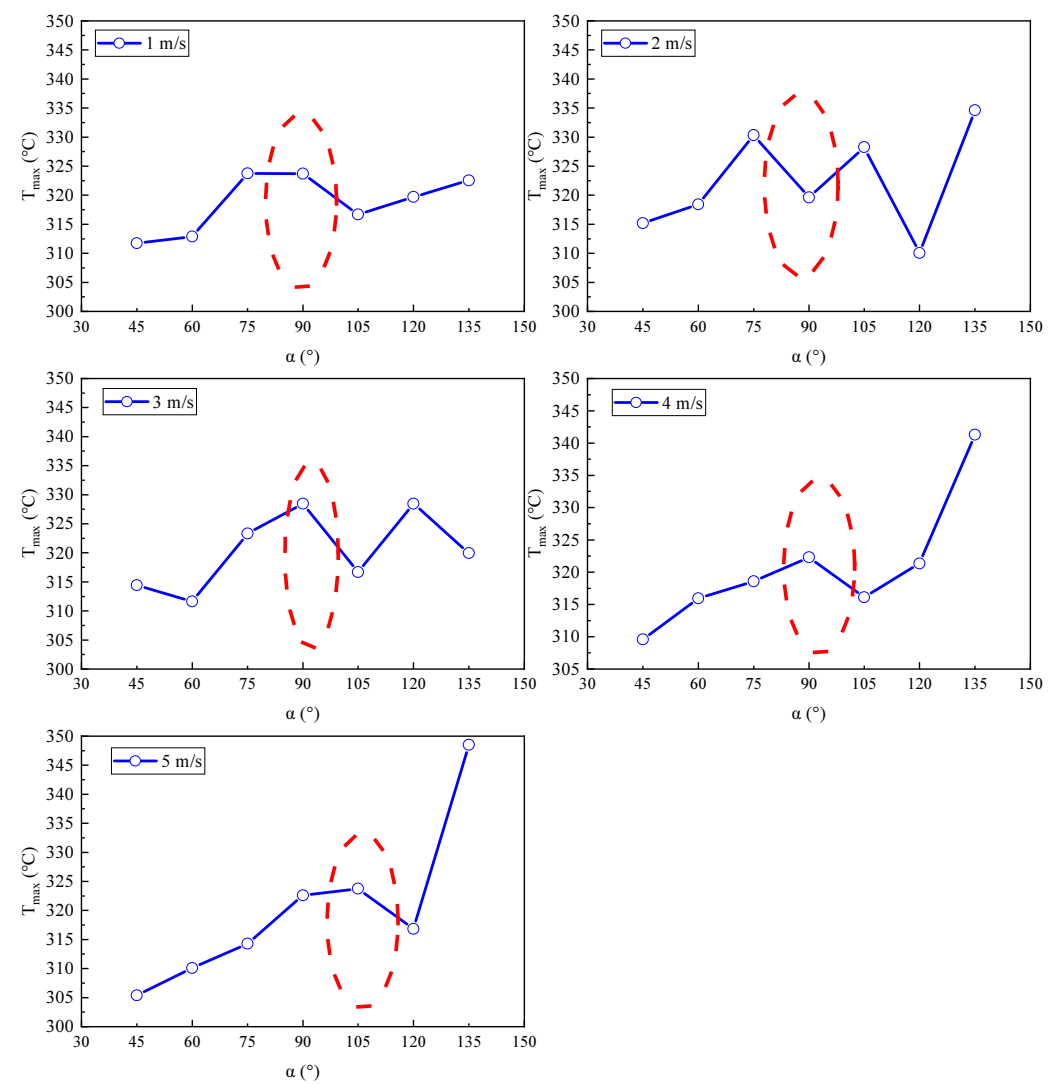

Figure 6. Maximum ceiling gas temperature. 

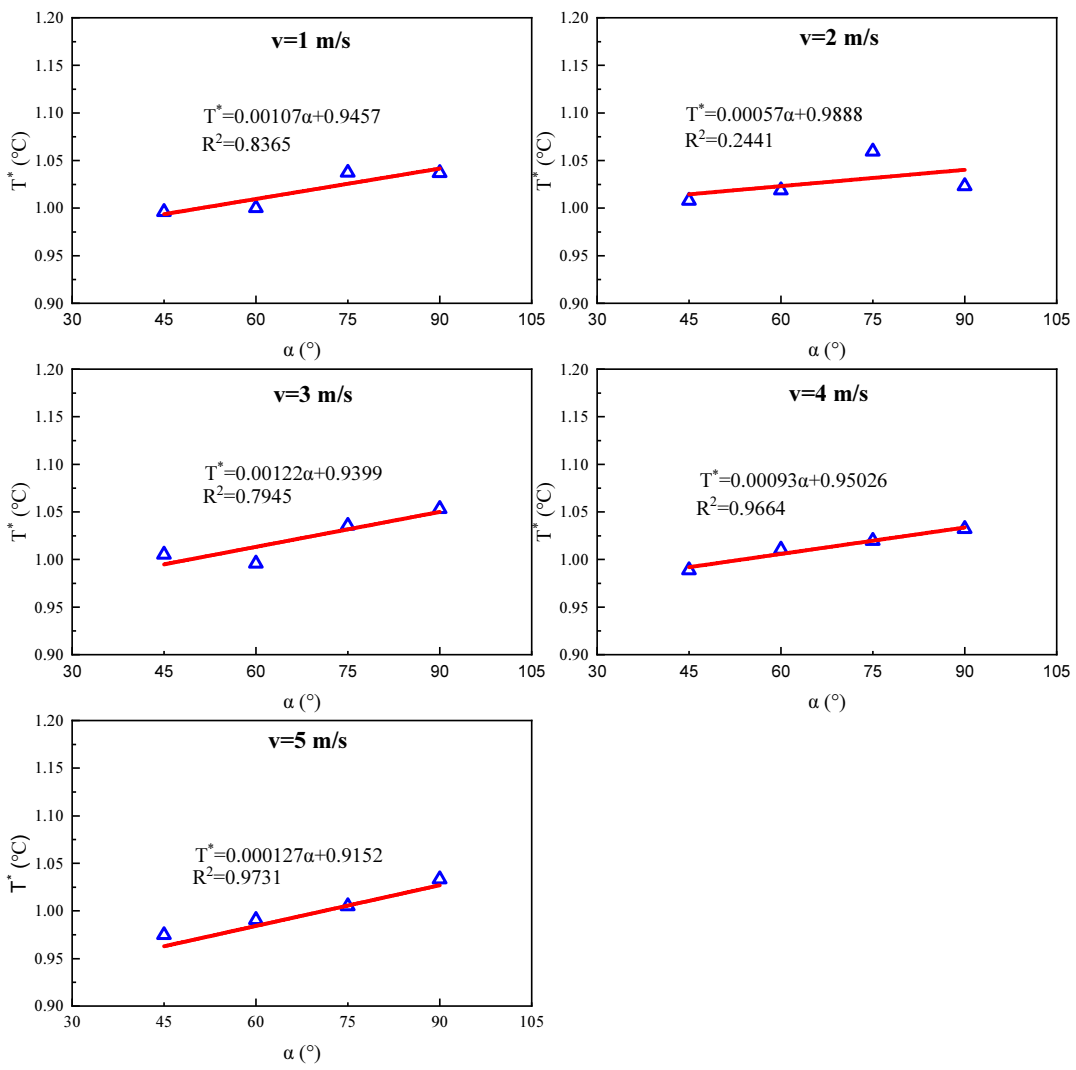

Figure 7. Dimensionless ceiling maximum temperature rise in different ambient wind velocity

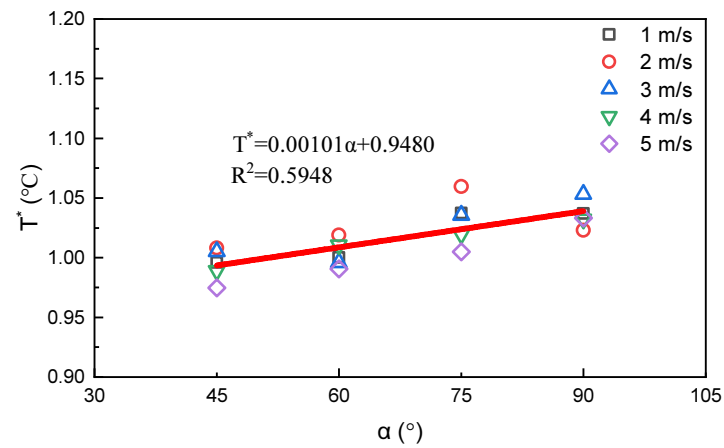

Figure 8. Dimensionless ceiling maximum temperature rise fitting with $\alpha\left(45^{\circ} \sim 90^{\circ}\right)$ 


\section{Conclusions}

In order to study the influence of ambient wind on smoke flow characteristics of natural ventilation in one end blocked tunnel, FDS was used to carry out a series of simulation and analyze the characteristics of smoke flow and temperature distribution in the tunnel, and the following conclusions were drawn:

(1) With the increase of wind speed $v$, the disturbance degree of air flow in the tunnel blocked by ambient wind increases, and the difficulty of smoke natural discharge increases accordingly.

(2) When $45^{\circ} \leq \alpha \leq 135^{\circ}$, the natural smoke exhaust capacity in the tunnel sealed at one end increases with the increase of $\alpha$.

(3) With the increase of wind speed $v$, ambient wind is more likely to enter the tunnel and mix with the smoke flow, making the vertical distribution of temperature near the open end of the tunnel more uniform.

(4) When the wind direction Angle $\alpha$ is within $45^{\circ} \sim 135^{\circ}$, the maximum temperature of tunnel ceiling has an increasing trend with the increase of $\alpha$.

(5) under the experimental conditions of this paper, dimensionless ceiling maximum temperature rise $T^{*}$ in one end blocked tunnel follows vary linearly with angle $\alpha$.

In this paper, the influence of ambient wind on smoke flow characteristics of natural ventilation in one end blocked tunnel is explored. In the future, other factors such as different fire source location and fire heat release rate may change the influence of environmental wind on the smoke flow characteristics of natural ventilation in the tunnel sealed at one end are considered for further exploration.

\section{Reference}

[1] Hu L., Fong N.K., Yang L., Chow W.K., Li Y., Huo R., Modeling fire-induced smoke spread and carbon monoxide transportation in a long channel: fire dynamics simulator comparisons with measured data, Journal of Hazardous Materials, 140 (2007) 293-298.

[2] Han J., Liu F., Wang F., Weng M., Wang J., Study on the smoke movement and downstream temperature distribution in a sloping tunnel with one closed portal, International Journal of Thermal Sciences, 149 (2020) 106165.

[3] Weng M.C., Yu L.X., Liu F., Nielsen P.V., Full-scale experiment and CFD simulation on smoke movement and smoke control in a metro tunnel with one opening portal, Tunnelling and underground space technology, 42 (2014) 96-104.

[4] Yao Y., Cheng X., Zhang S., Zhu K., Zhang H., Shi L., Maximum smoke temperature beneath the ceiling in an enclosed channel with different fire locations, Applied Thermal Engineering, 111 (2017) 30-38.

[5] Fan C., Zhang L., Jiao S., Yang Z., Li M., Liu X., Smoke spread characteristics inside a tunnel with natural ventilation under a strong environmental wind, Tunnelling and underground space technology, 82 (2018) 99-110.

[6] Fan C.G., Jin Z.F., Zhang J.Q., Zhu H.Y., Effects of ambient wind on thermal smoke exhaust from a shaft in tunnels with natural ventilation, Applied Thermal Engineering, 117 (2017) 254-262.

[7] Zhao W., Ouyang R., Ran Q., Chen T., Xu Z., Zou M., Fan C., An experimental study on smoke backlayering and critical velocity in tunnel fires with canyon cross wind, Journal of Wind Engineering and Industrial Aerodynamics, 209 (2021) 104477.

[8] Yi L., Luan D., Yang L., Chen T., Tao H., Xu Z., Fan C., Flow field and fire characteristics inside a tunnel under the influence of canyon cross wind, Tunnelling and Underground Space Technology, 105 (2020) 103575.

[9] Chen T., Li Y., Luan D., Jiao A., Yang L., Fan C., Shi L., Study of flow characteristics in tunnels induced by canyon wind, Journal of Wind Engineering and Industrial Aerodynamics, 202 (2020) 104236.

[10] Yao Y., Li Y.Z., Ingason H., Cheng X., Scale effect of mass loss rates for pool fires in an open environment and in tunnels with wind, Fire safety journal, 105 (2019) 41-50. 
[11] Yi L., Chen Y., Bu R., Luo C., Zhou Y., Visualization study on the effect of ambient wind on smoke layer height in chamber fires under natural smoke exhaust condition, Journal of Wind Engineering and Industrial Aerodynamics, 208 (2021) 104458.

[12] Tanaka F., Kawabata N., Ura F., Effects of a transverse external wind on natural ventilation during fires in shallow urban road tunnels with roof openings, Fire Safety Journal, 79 (2016) 20-36.

[13] Nyman H., Sandberg M., The influence of external wind in tunnels, International Journal of Ventilation, 10 (2011) 31-48.

[14] Kubwimana T., Salizzoni P., Bergamini E., Mos A., Méjean P., Soulhac L., Wind-induced pressure at a tunnel portal, Environmental Fluid Mechanics, 18 (2018) 769-786.

[15] Jiao A., Shen Y., Wang Z., Chen T., Tao H., Xu Z., Fan C., Experimental study on the effect of canyon cross wind yaw angle on airflow and flame characteristics in a tunnel, Journal of Wind Engineering and Industrial Aerodynamics, 213 (2021) 104616.

[16] Shen Y., Jiao A., Chen T., Li Y., Gao Y., Xu Z., Jiang B., Fan C., Experimental study on smoke movement characteristics in tunnel fires with different canyon cross wind yaw angles, Tunnelling and Underground Space Technology, 117 (2021) 104129.

[17] Jing H., Liao H., Ma C., Tao Q., Jiang J., Field measurement study of wind characteristics at different measuring positions in a mountainous valley, Experimental Thermal and Fluid Science, 112 (2020) 109991. 